\title{
Efficacy and complication of endoscopic submucosal dissection for superficial esophageal carcinoma: a systematic review and meta-analysis
}

\author{
Fenghao Sun, Ping Yuan, Tianxiang Chen and Jian $\mathrm{Hu}^{*}$
}

\begin{abstract}
Aim: For patients with superficial esophageal carcinoma, ESD was one of treatment modalities to remove the lesion safely and effectively. We perform this meta-analysis to determine the efficacy and incidence of complication of ESD for patients with superficial esophageal carcinoma.

Method: Articles were searched in MEDLINE (PubMed and Ovid), Cochrane Database of Systemic Reviews, Google scholar, and Web of Science. Two reviewers independently searched and extracted data. Meta-analysis of the efficacy of ESD was analyzed by calculating pooled en bloc and RO resection rate. Incidence of complications such as perforation, stenosis and mediastinal emphysema was also calculated. Pooling was conducted using either fixed-effects model or random-effects model depending on the heterogeneity across studies.

Results: 21 studies (1152 patients and 1240 lesions) were included in this analysis. The pooled en bloc resection rate was 99\% (95\% Cl 99\%-100\%). Stratified by tumor size, en bloc resection rates did not show any significant difference. The pooled R0 resection rate was 90\% (95\% Cl 87\%-93\%). The pooled R0 resection rate was 85\% (95\% Cl, $80 \%-90 \%)$ for large tumor and $92 \%$ (95\% Cl, 87\%-93\%) for small tumor $(p<0.001)$. Stenosis served as the most common reported complication with pooled incidence of 5\% (95\% Cl 3-8\%), followed by perforation (1\%, $95 \% \mathrm{Cl}$ $0-1 \%)$ and mediastinal emphysema ( $0 \% \mathrm{Cl} 0-1 \%)$. The incidence of postoperative stenosis decreased significantly after 2011 (2\%, 95\% Cl 0-3\%) compared with that before 2011 (9\%, 95\% Cl 3-8\%) $(p<0.001)$.
\end{abstract}

Conclusion: ESD was an efficient modality for treating superficial esophageal carcinoma, with perfect en bloc and RO resection rate and low complication rate. The most common complication of ESD was stenosis. Although recurrence rate was low, patients should be maintained in a scheduled surveillance program.

Keywords: Superficial esophageal carcinoma, Endoscopic submucosal dissection (ESD), en bloc, R0 resection rate

\section{Review} Introduction

An increasing number of esophageal carcinoma is diagnosed worldwide each year [1]. With the improving of diagnostic technology, esophageal cancer can be diagnosed in early stage. Endoscopic treatment of early esophageal carcinoma has been increasingly conducted around the world, which aims to maintain the integrity of the esophagus and avoid the considerable morbidity and mortality of esophagectomy. Endoscopic mucosal resection (EMR) was the first developed endoscopic

\footnotetext{
*Correspondence: hujian_med@163.com

Department of Thoracic surgery, First Affiliated Hospital, Zhejiang University, Hangzhou, Zhejiang Province, China
}

(c) 2014 Sun et al.; licensee BioMed Central Ltd. This is an Open Access article distributed under the terms of the Creative

resection strategy. However, EMR is sometimes associated with local recurrence, especially when lesions larger than $20 \mathrm{~mm}$ are resected in a piecemeal manner [2]. To overcome the limitation of EMR, endoscopic submucosal dissection (ESD) was developed about 10 years ago [3]. ESD allows en bloc resection regardless of the size and precise histological assessment of the specimens $[4,5]$. The best result of ESD is that tumors are excised in one piece with tumor-free lateral basal margins (R0 resection), therefore preventing residual disease and local margins.

Recently, a number of studies were conducted to assess the efficacy and durability of ESD. However, the results of these studies were rather controversial with the R0 resection rate ranging from $71 \%$ to $97 \%[6,7]$. 
Although ESD has been recently recognized as one of the standard treatments for superficial esophageal carcinoma (SEC) in Japan [8], it is highly technique demanding because the wall of the esophagus is thinner than that of stomach and the narrow lumen of the esophagus restricts endoscopic manipulation. As a result, life-threatening complications such as perforation and mediastinal emphysema occur with the incidence of 4-10\% [8-10].

We perform this meta-analysis to: (1) analysis the en bloc and R0 resection rate of ESD for SEC; (2) analysis the local recurrence rate after ESD; (3) analysis the incidence of complications of ESD to treat SEC.

\section{Methods}

\section{Search strategy}

This study was conducted following the Meta-analysis Of Observational Studies in Epidemiology guidelines [11]. Electronic literature searches were conducted from 1 January 1980 to 1 December 2013. MEDLINE (PubMed and Ovid), Cochrane Database of Systemic Reviews, Google scholar, and Web of Science were searched for eligible studies. A systemic literature search was performed with the search term "(ESD OR endoscopic submucosal dissection) AND esophag"." References of all relevant articles were also scanned for potential missing studies. Articles with full text in English were retrieved. The retrieved studies were carefully examined to avoid potential duplicates or overlapping data. No attempt was made to locate unpublished material or contact researchers for unpublished data.

\section{Study selection and review process}

To be eligible, studies had to meet the following criteria: (1) esophageal cancer was histologically proven; (2) ESD (not EMR) was conducted; (3) En bloc or R0 resection rate was reported (4) no age or gender restrictions; (5) published in a peer-reviewed journal from 1 January 1980 to 1 December 2013.

We excluded: (1) non-English language studies; (2) nonhuman studies; (3) reviews and case reports; (4) studies with mean follow up periods less than 6 months; (5) studies with less than 20 patients; (6) study samples that are duplicatly reported.

\section{Data collection and quality assessment}

Data were collected independently by two investigators (Fenghao Sun and Ping Yuan) from each study using a predefined data table, with disagreements being resolved by consensus. For each study, the following characteristics were collected: first author's name, year of publication, number of patients, the country in which the study was carried out, study design, faculty, kinds of knife and hooks that was used, ESD and surveillance protocol, en bloc and R0 resection rate, time of procedure, occurrence and types of complications, histopathologic types of biopsies and follow up evaluation time. Recorded patient characteristics included age and gender. The quality of each study was assessed using the previously validated Downs and Black [12] instrument, which can assess both randomized and nonrandomized studies. After abstraction, the authors reviewed the evidence tables and discrepancies again were resolved by consensus.

\section{Efficacy outcomes and complications}

The primary efficacy outcomes were en bloc resection, defined as the complete removal of the tumor including the markings into one nonfragmented piece, and R0 resection, defined as complete tumor removal with both lateral and deep margins free of neoplastic cells.

Efficacy outcomes were tabulated according to lesion size (The maximum diameter of the lesion was considered to be the lesion size). The primary durability outcome was local recurrence rate of neoplasm defined histologically after R0 resection. Complications (most commonly perforation, stenosis, mediastinal emphysema and bleeding) were recorded as secondary outcomes. These were ascertained based on the individual study definitions of adverse events. Generally, perforation was diagnosed during ESD. Mediastinal emphysema was diagnosed by the presence of air in the mediastinal space on a chest radiograph or CT scan. Bleeding was defined when patients required blood transfusion during procedure, or a postoperative bleeding that required hemostatic treatment such as endoscopic clipping and coagulation. Stenosis was defined as a stricture that required endoscopic treatment.

\section{Statistical analysis}

Statistical analysis was performed using Stata version 12.1 (Stata Corp LP, College Station, TX). En bloc and R0 resection rates were pooled by either fixed-effects model or random-effects model depending on the heterogeneity across studies. A random-effect model was applied if heterogeneity was significant; otherwise, a fixed-effects model was adopted. $\mathrm{I}^{2}$ and Cochran's Q tests were performed to assess the heterogeneity across studies (for the Cochran Q test, heterogeneity was present if $\mathrm{P}<0.05$, while values of $\mathrm{I}^{2}$ to 25,50 , and $75 \%$ represented low, moderate, and high heterogeneity, respectively) [13]. To identify potential sources of heterogeneity, analyses were repeated for each subset of the studies. Additional stratified analysis were performed by sample size $(D \geq 25 \mathrm{~mm}$ vs $D<25 \mathrm{~mm}, 25 \mathrm{~mm}$ is the mean diameter of all the lesions of included studies) and year of publication (before 2011 vs after 2011). Although ESD has been improving all the time, there was no turning point where a revolutionary improvement took place. 
We want to find out whether ESD outcomes have been improved in this decade compared with last decade. All $p$ values presented were two-sided. The association was considered significant if the $p$ value was less than 0.05 .

\section{Results}

\section{Search results}

After initial search, 729 articles were identified (Figure 1). Among these, 643 were excluded after the first screening based on abstracts and titles. An additional 65 records were excluded after abstract and full-text review for reasons such as non-English language $(\mathrm{n}=2)$, irrelevant report $(n=14)$, reviews $(n=8)$, fewer than 20 subjects $(n=6)$, mean follow up less than 6 month $(n=2)$, duplicate reports of study samples $(n=1)$, meeting abstract $(n=2)$, no data of either en bloc or R0 resection rate $(\mathrm{n}=13)$, SEC originating from the muscularis propria layer $(n=2)$, Sampling bias $(\mathrm{n}=4)$, combined data $(\mathrm{n}=3)$, animal report $(n=2)$, case reports and letters $(n=6)$. Therefore, 21 studies with 1152 patients (1240 lesions) which met the inclusion criteria were included [2,4-10,14-29].

\section{Study characteristics}

Included studies were published between 2005 and 2013. All but three studies were performed in Japan. The other 3 studies were performed in China, Brazil and Italy, respectively. There were two studies lacking en bloc resection rate and one study $\mathrm{R} 0$ resection rate. Substantial variability exists in terms of number of patients and instruments. The majority of studies used insulationtipped knife (IT knife), hook knife, needle knife, or the combination of these knives. Number of patients ranged from 20 to 138. The number of lesions that exceeded $3 / 4$ of esophageal circumference was available only in 6 studies. As for histopathology, 12 studies included squamous cell carcinoma, 8 included adenocarcinoma, and 5 included high-grade dysplasia. Mean follow up period ranged from 12 to 53 months. Four studies did not declare a specific follow-up period but noted to be at least 12 months. Mean ages of patients were around 70 with only one exception. 5 studies did not specify age information. The majority of included patients were male. The characteristics for all included studies

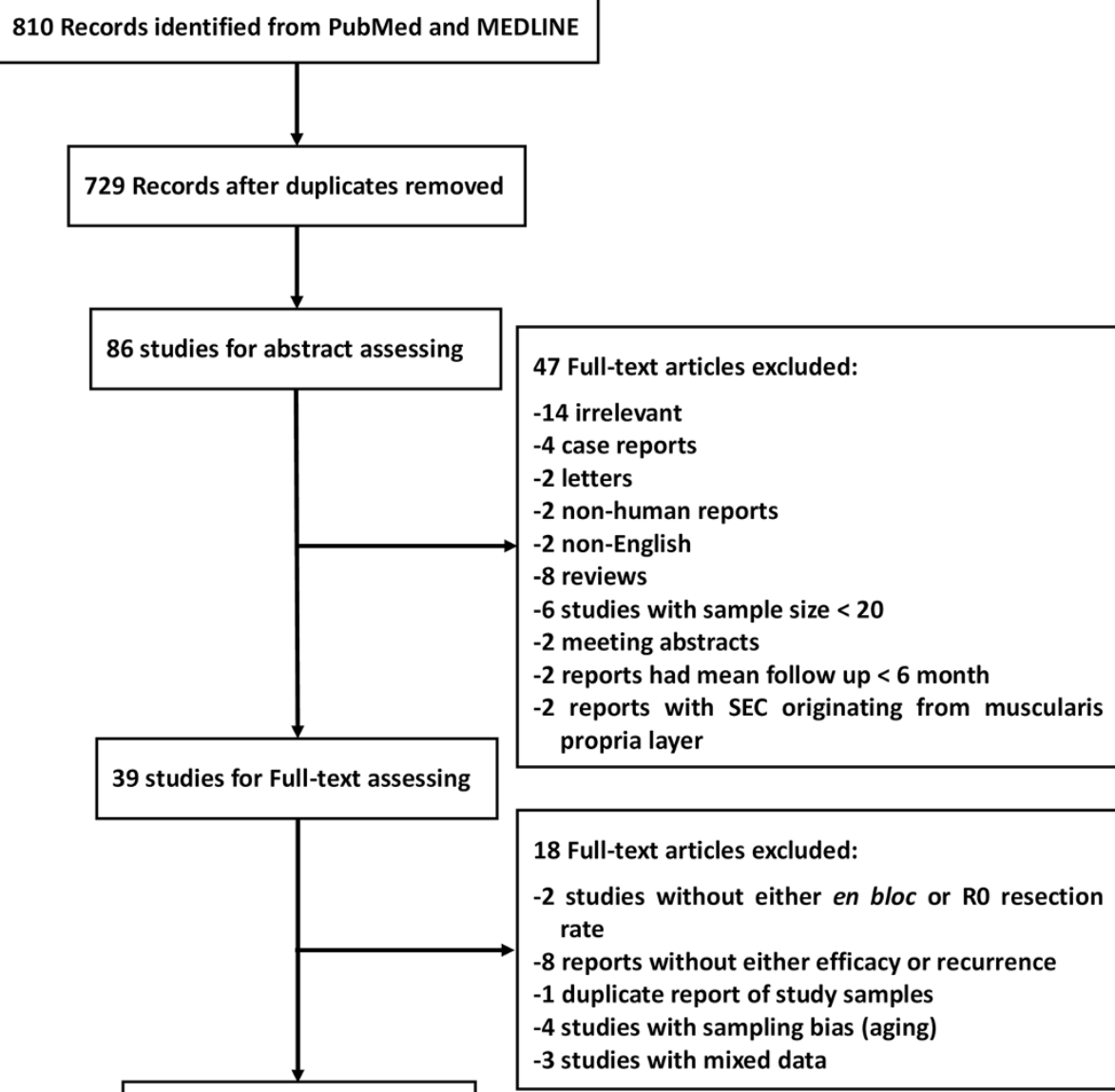

21 Full- text articles included

Figure 1 Study flow diagram. 
were shown in Table 1. All studies were published as full-text articles.

\section{Efficacy outcomes}

The pooled en bloc resection rate was 99\% (95\% CI 99\%$100 \%)$. Stratified by tumor size, en bloc resection rates did not show any difference. The polled en bloc resection rate was $99 \%$ (95\% CI, 98\%-100\%) for large tumor $(\mathrm{D} \geq 25 \mathrm{~mm})$ and $100 \%$ (95\% CI, 99\%-100\%) for small tumor (Figure 2).

The pooled R0 resection rate was 90\% (95\% CI 87\%93\%). The pooled R0 resection rate was $85 \%$ (95\% CI, 80\%-90\%) for large tumor and 92\% (95\% CI, 87\%-93\%) for small tumor $(p<0.001)$ (Figure 3$)$.

\section{Complications and recurrence}

Stenosis served as the most common reported complication with pooled incidence of 5\% (95\% CI 3-8\%) (Figure 4), followed by perforation (1\%, 95\% CI 0-1\%) (Figure 5) and mediastinal emphysema $(0 \%, 95 \%$ CI $0-1 \%)$ (Figure 6). Tumor size did not show influence on incidence of perforation and stenosis. The incidence of postoperative stenosis decreased significantly after 2011 (2\%, 95\% CI 0-3\%) compared with that before 2011 (9\%, 95\% CI 3-8\%) $(p<0.001)$ (Figure 7). However, this trend was not found in the incidence of perforation (Figure 8). The pooled incidence of mediastinal emphysema was 0\% (95\% CI 0-1\%) (Figure 6). Since mediastinal emphysema occurred only in 20 patients distributed in 6 studies, subgroup analysis would be unnecessary.

Our data showed that only 5 out of 1159 patients developed histopathologically identified local recurrence. 3 of them were managed by an additional ESD and 1 of them underwent EMR and 2 sessions of radiofrequency ablation (RFA) and the other one was not declared.

\section{Heterogeneity}

Significant heterogeneity was only found in R0 resection rate $\left(\mathrm{I}^{2}=54.6 \%, p<0.001\right)$ and incidence of stenosis $\left(\mathrm{I}^{2}=\right.$ $76.0 \%, p<0.001)$.

\section{Discussion}

ESD has been recognized as a reliable treatment for early gastric neoplasms and has been gradually accepted as a preferred method for the endoscopic treatment of SEC [30]. However, the use of ESD for SEC is not well guided. Patients and physician need to be well informed with the risks and benefits of the procedure. In this systematic review and meta-analysis, 1152 patients (1240 lesions) of 21 studies were included. The pooled en bloc (99\%, 95\% CI 99-100\%) and R0 (90\%, 95\% CI 87-93\%) resection rates were calculated. We also evaluated the incidence of complication such as perforation (1\%, 95\% CI $0-1 \%)$, stenosis $(5 \%, 95 \%$ CI $3-8 \%)$ and mediastinal emphysema (0\%, 95\% CI 0-1\%). Local recurrence only occurred in 5 patients. Subgroup analysis was also conducted by tumor size and year of publication. For en bloc resection rate, no significant difference was detected between large $(\mathrm{D} \geq 25 \mathrm{~mm})$ and small tumor $(\mathrm{D}<25 \mathrm{~mm})$. For R0 resection rate, large tumor (85\%, 95\% CI 80-90\%) had a lower R0 resection rate compared with small tumor (92\%, 95\% CI 89-95\%). Most studies reported the en bloc resection rate of over 95\% except for two. One study reported by Repici et al. had an en bloc resection rate of $90 \%$, probably because of the extremely large tumor size $($ mean $=33 \mathrm{~mm})$ [9]. The other one conducted by Arants et al. reported an en bloc resection rate of $92 \%$ which might be resulted from its submucosal tunnel dissection procedure instead of circumferential mucosal incision [14]. All but one study achieved R0 resection rate of more than $80 \%$.

ESD for esophageal cancer had been proven to be superior to conventional EMR in terms of the R0 resection rate and the recurrence rate [31]. With ESD, en bloc resection can be achieved regardless of the size of the tumor [4]. It was also proved in our study that en bloc resection rate did not drop in large tumors. However, R0 resection rate was influenced by the tumor size. Larger tumors were less likely to achieve R0 resection. The reason for such a phenomenon was understandable that resection of larger tumor was more technique-demanding. In this perspective, though ESD can achieve R0 resection in large tumors, the R0 resection rate drops.

The risk of complication is unavoidable since ESD is an endoscopic surgical procedure. Perforation was considered the most common complication during ESD procedures [31]. But our data demonstrated that the perforation rate was only $1 \%$ (95\% CI, $0-1 \%)$, while the incidence of postoperative stenosis was 5\% (95\% CI, 3-8\%), making stenosis the major complication for ESD. A similar result was reported by Sgourakis et al. that the perforation and stenosis rate were $1.8 \%$ and $12.2 \%$ respectively [32]. Perforation was considered as the most severe complications during ESD procedure. Although it can be temporarily clipped by hemoclips, unstable vital signs during the procedure might result in an urgent operation $[3,30]$. Sgourakis G et al. reported that esophageal stenosis was statistically more prevalent among patients managed with ESD than EMR [32]. As for mediastinal emphysema, the occurrence of the complication was rare according to the studies included.

Interestingly, significant difference of stenosis occurrence was found before and after the year of 2011, with a trend toward reduced occurrence of stenosis after $2011(p<0.001)$. It was reported that a mucosal defect involving more than three-fourths of the esophageal circumference was significantly associated with the development of severe esophageal stricture after EMR [33]. 
Table 1 Characteristics of included studies

\begin{tabular}{|c|c|c|c|c|c|c|c|c|c|c|c|c|}
\hline Study & Year & Country & No. patients & No. lesion & $\begin{array}{l}\text { Mean } \\
\text { age }\end{array}$ & $\begin{array}{l}\text { Mean tumor } \\
\text { size }(\mathrm{mm})\end{array}$ & $\begin{array}{l}\text { No. of lesions that } \\
\text { exceed } 3 / 4 \text { of esophageal } \\
\text { circumference }\end{array}$ & Knife & $\begin{array}{l}\text { Complication } \\
\text { stenosis/ } \\
\text { perforation/ } \\
\text { mediastinal } \\
\text { emphysema }\end{array}$ & $\begin{array}{l}\text { Follow up } \\
\text { period, mo }\end{array}$ & $\begin{array}{l}\text { Local } \\
\text { recurrence }\end{array}$ & $\begin{array}{l}\text { Quality } \\
\text { score }\end{array}$ \\
\hline Arantes. V & 2013 & Brazil & 23 & 25 & 68 & 25 & $3(12 \%)$ & Flush Knife & $0 / 1 / 2$ & 21 & 2 & 20 \\
\hline Higuchi. K & 2013 & Japan & 52 & 52 & 68 & 20 & ND & IT knife/Hook-knife/Needle knife & $5 / 0 / 0$ & $>12$ & 0 & 22 \\
\hline Fujinami. $\mathrm{H}$ & 2013 & Japan & 35 & 38 & 68 & 31.9 & ND & Stag beetle/Hook knife & $0 / 1 / 8$ & $>12$ & 1 & 20 \\
\hline Sohara. N & 2013 & Japan & 59 & 64 & 68 & 23 & ND & NR & $0 / 1 / 0$ & 24 & 0 & 22 \\
\hline Imai. K & 2013 & Japan & 49 & 50 & 72 & ND & ND & IT knife & $3 / 0 / 0$ & 47 & 0 & 23 \\
\hline Omae. M & 2013 & Japan & 44 & 44 & 70 & 17 & ND & IT knife & 0/0/0 & 33 & 0 & 18 \\
\hline Toyonaga. $T$ & 2013 & Japan & 138 & 138 & 69 & 23 & ND & IT knife/Hook-knife/Needle knife & 0/0/0 & 53 & 0 & 19 \\
\hline Lee. C T & 2012 & China & 20 & 24 & 48 & 33.7 & $2(8.3 \%)$ & IT knife & $3 / 1 / 1$ & 12 & 0 & 22 \\
\hline Yamashita. T & 2011 & Japan & 71 & 71 & NR & 30 & $11(15.4 \%)$ & IT knife/needle knife & $6 / 1 / 0$ & 39 & 0 & 21 \\
\hline Urabe. Y & 2011 & Japan & 59 & 79 & 65 & ND & ND & IT knife/Hook knife & $4 / 6 / 0$ & 36 & 0 & 22 \\
\hline Nonaka. K & 2010 & Japan & 25 & 27 & NR & 21 & ND & Hook knife/Flash knife/flex knife & $3 / 1 / 0$ & $>12$ & 0 & 22 \\
\hline Hirasawa. K & 2010 & Japan & 58 & 58 & 69 & 37.7 & ND & IT knife/Needle knife & $1 / 0 / 0$ & 30 & 0 & 21 \\
\hline Takahashi. H & 2010 & Japan & 116 & 116 & 67 & 30 & $26(22 \%)$ & Hook knife/Needle-knife & $20 / 3 / 0$ & 36 & 0 & 23 \\
\hline Repici. A & 2010 & Italy & 20 & 20 & 64 & 32 & ND & IT knife/Hook knife & $1 / 0 / 2$ & 36 & 0 & 20 \\
\hline Ishii. N & 2010 & Japan & 35 & 37 & 67 & 22 & ND & Hook knife/Flex knife & $9 / 0 / 0$ & 19 & 0 & 20 \\
\hline Ono. S & 2009 & Japan & 84 & 107 & NR & 22.9 & $10(9.3 \%)$ & Flex knife/Splash needle & $15 / 4 / 1$ & 21 & 1 & 22 \\
\hline Fujishiro. M & 2009 & Japan & 79 & 102 & NR & 22 & $9(8.8 \%)$ & Flex-knife/Splash-needle & $13 / 4 / 0$ & 25 & 1 & 16 \\
\hline Ishihara. R & 2008 & Japan & 29 & 31 & 64 & 16 & ND & Hook-knife & $3 / 1 / 0$ & $>12$ & 0 & 21 \\
\hline Yoshinaga. S & 2008 & Japan & 24 & 25 & 62 & 16.5 & ND & IT knife & $2 / 0 / 0$ & 31 & 0 & 21 \\
\hline Kakushima. N & 2006 & Japan & 30 & 30 & 70 & 22.5 & ND & Flex knife & $0 / 1 / 0$ & 15 & 0 & 20 \\
\hline Oyama. M & 2005 & Japan & 102 & 102 & NR & 28 & ND & Hook knife & $7 / 0 / 6$ & 21 & 0 & 17 \\
\hline
\end{tabular}




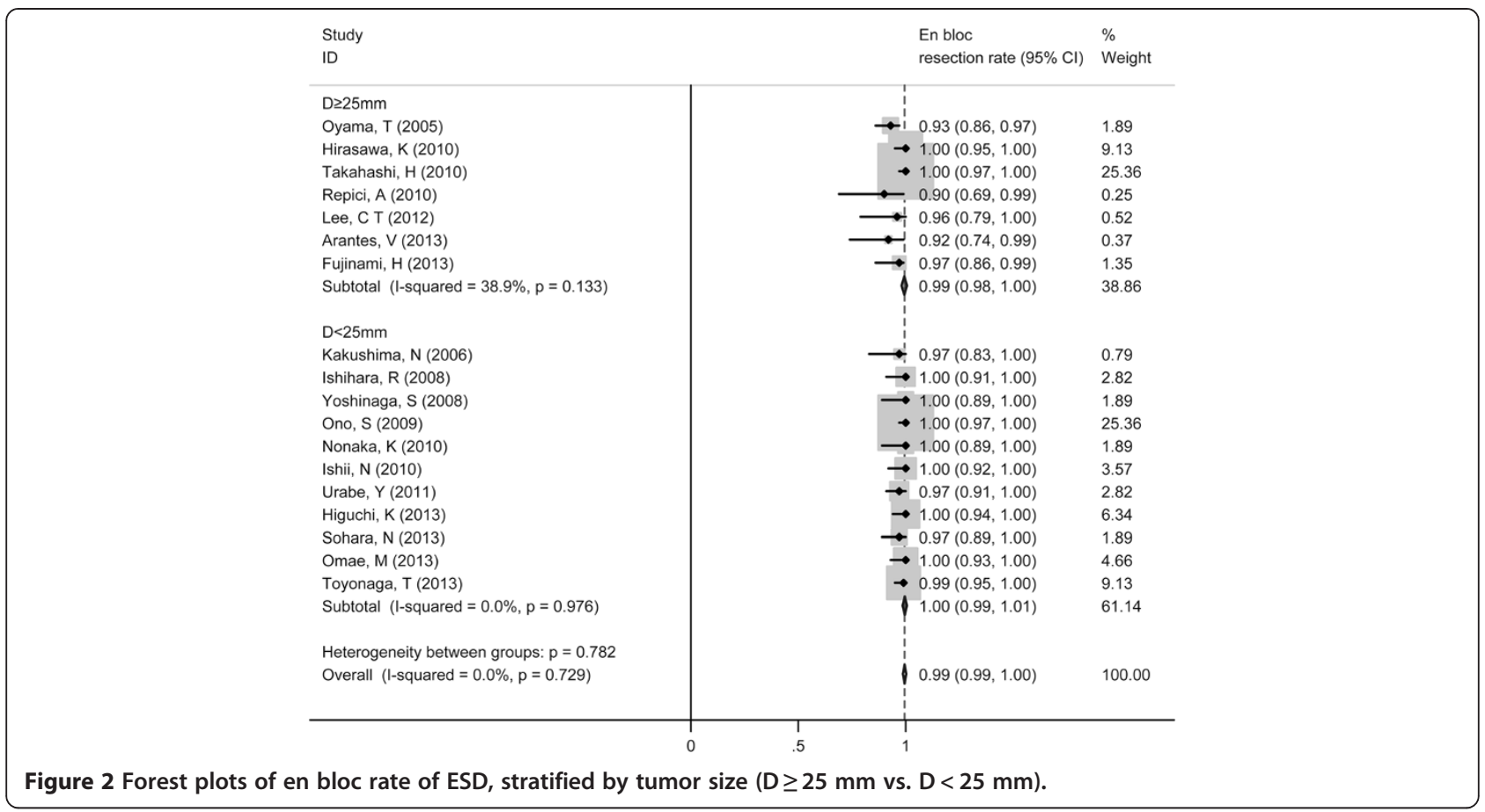

Ono et al. also revealed that circumferential extension and histologic depth of lesion can be reliable independent predictors for postoperative stenosis [34]. However, with only 6 studies specified the number of lesions that exceeded 3/4 of esophageal circumference, it is hard to evaluate the relationship in this study. Instead, we further confirmed in our study that tumor size did not show influence on incidence of perforation and stenosis. The possibility exists that a more rigorous selection of indications may contribute to the decreasing stenosis

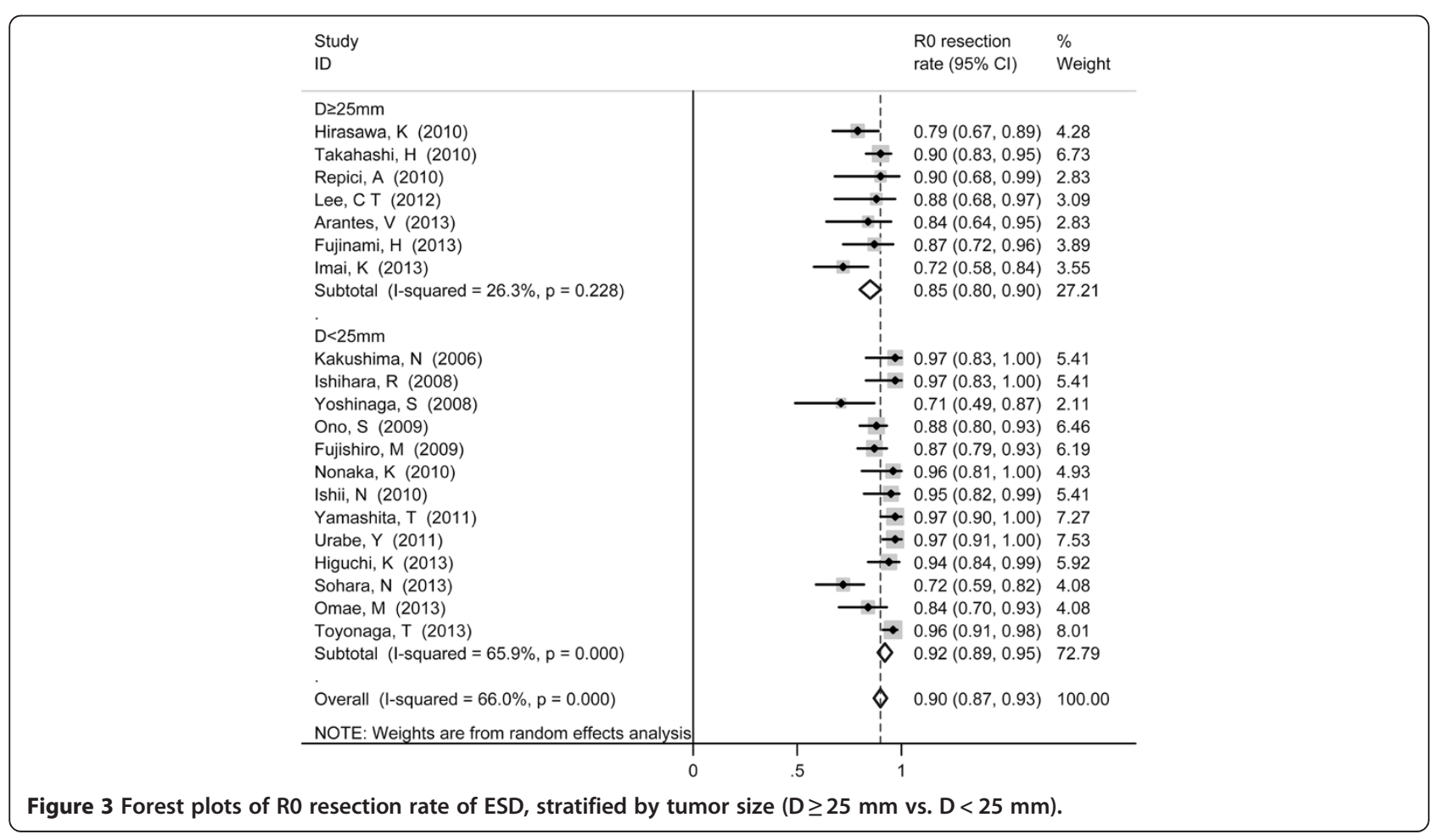




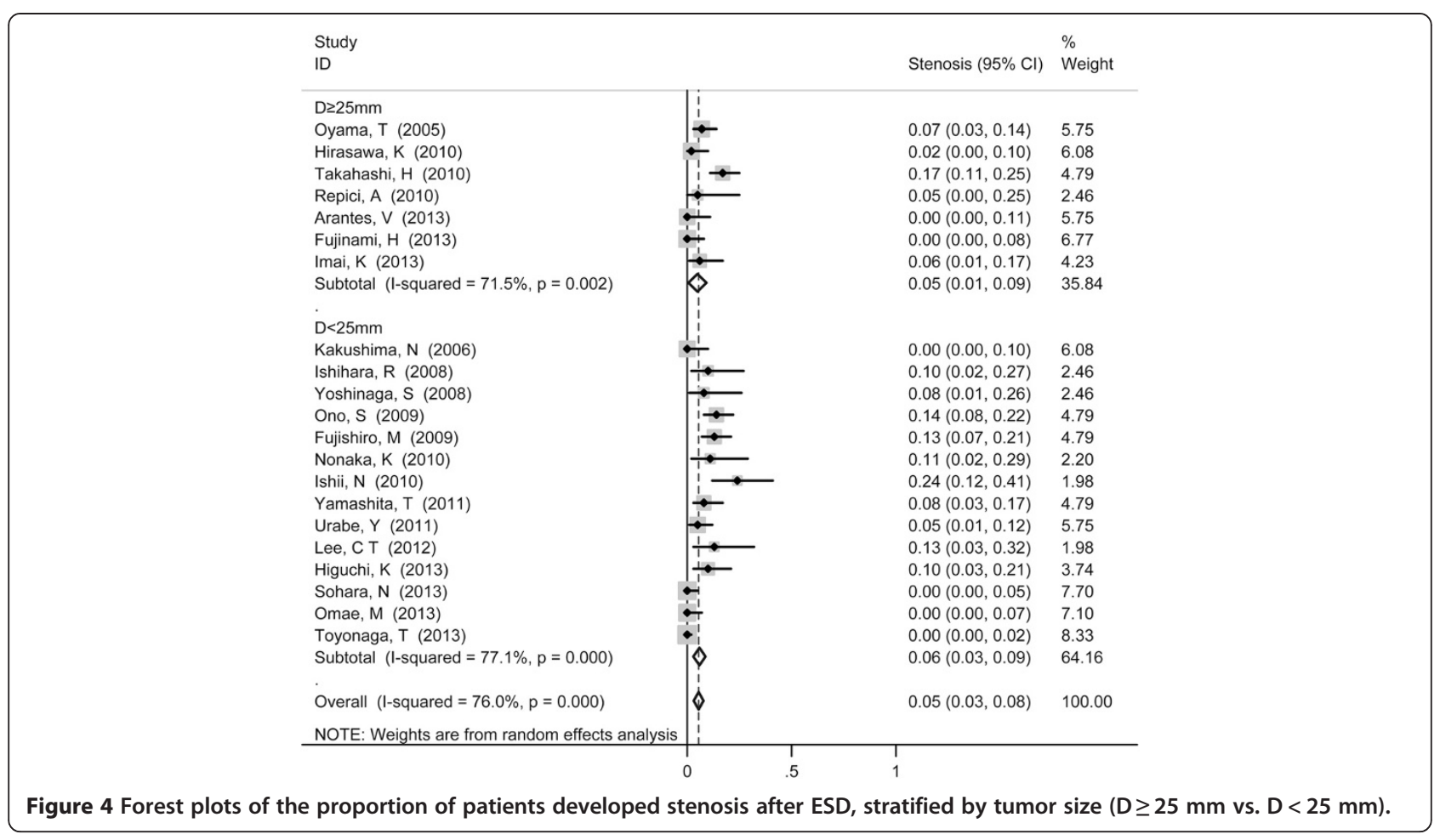

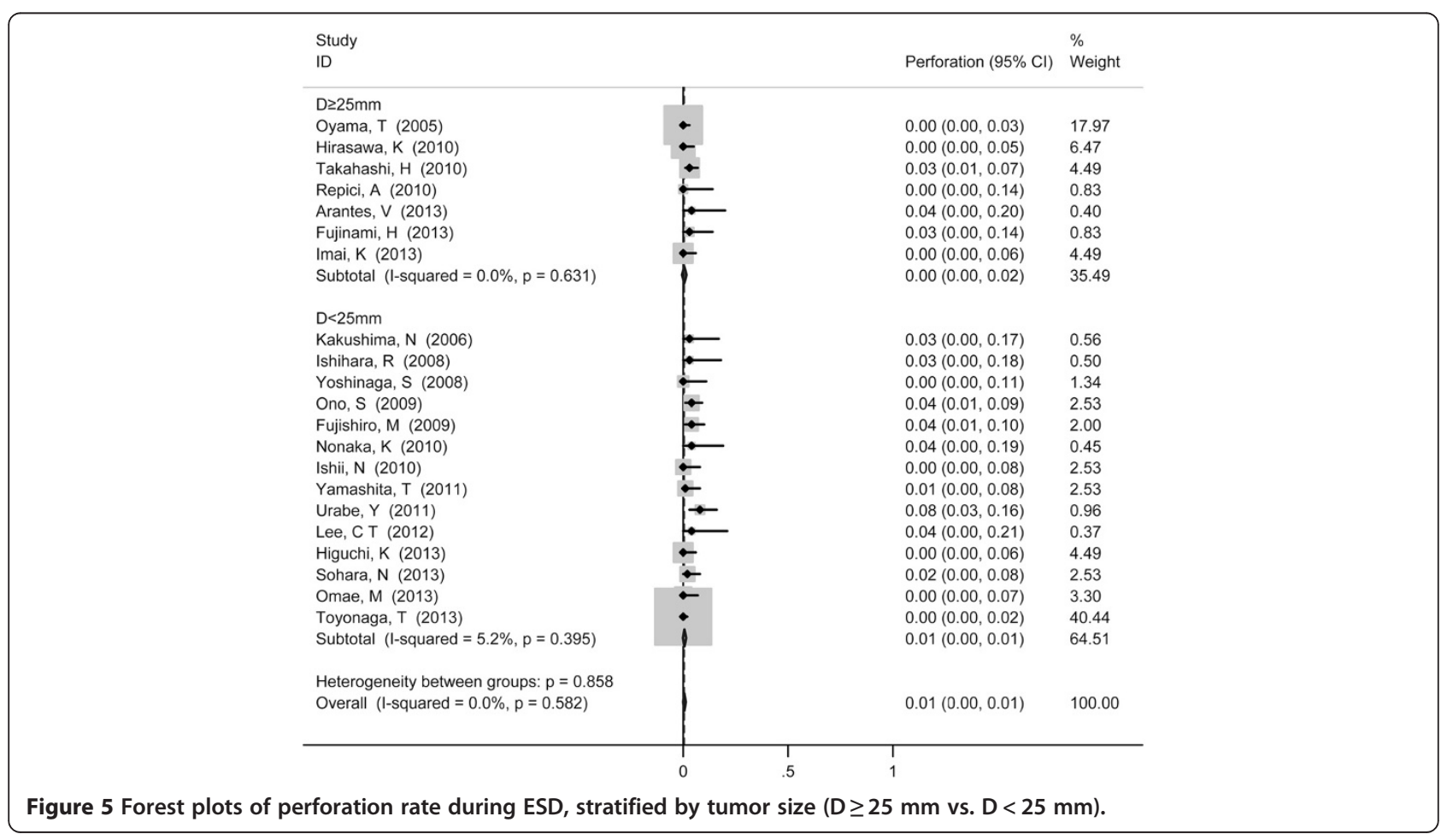




\begin{tabular}{|c|c|c|c|}
\hline \multicolumn{2}{|l|}{ Study } & \multirow[b]{2}{*}{ Stenosis $(95 \% \mathrm{Cl})$} & $\%$ \\
\hline ID & & & Weight \\
\hline After 2011 & & & \\
\hline Yamashita, T (2011) & $\rightarrow$ & $0.08(0.03,0.17)$ & 4.79 \\
\hline Urabe, Y (2011) & + & $0.05(0.01,0.12)$ & 5.75 \\
\hline Lee, C T (2012) & & $0.13(0.03,0.32)$ & 1.98 \\
\hline Arantes, V (2013) & $\frac{1}{1}$ & $0.00(0.00,0.11)$ & 5.75 \\
\hline Higuchi, K (2013) & 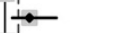 & $0.10(0.03,0.21)$ & 3.74 \\
\hline Fujinami, H (2013) & 4 & $0.00(0.00,0.08)$ & 6.77 \\
\hline Sohara, N (2013) & $\rightarrow$ & $0.00(0.00,0.05)$ & 7.70 \\
\hline Imai, K (2013) & $5-$ & $0.06(0.01,0.17)$ & 4.23 \\
\hline Omae, M (2013) & -1 & $0.00(0.00,0.07)$ & 7.10 \\
\hline Toyonaga, $\mathrm{T}(2013)$ & 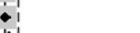 & $0.00(0.00,0.02)$ & 8.33 \\
\hline Subtotal (I-squared $=47.6 \%, p=0.046)$ & $b_{1}^{\prime}$ & $0.02(0.00,0.03)$ & 56.13 \\
\hline \multicolumn{4}{|l|}{ Before 2011} \\
\hline Oyama, T (2005) & $\rightarrow$ & $0.07(0.03,0.14)$ & 5.75 \\
\hline Kakushima, N (2006) & $\frac{1}{11}$ & $0.00(0.00,0.10)$ & 6.08 \\
\hline Ishihara, R (2008) & $\left.\right|^{+}$ & $0.10(0.02,0.27)$ & 2.46 \\
\hline Yoshinaga, S (2008) & in & $0.08(0.01,0.26)$ & 2.46 \\
\hline Ono, S (2009) & $1 \rightarrow$ & $0.14(0.08,0.22)$ & 4.79 \\
\hline Fujishiro, M (2009) & $1 \rightarrow$ & $0.13(0.07,0.21)$ & 4.79 \\
\hline Nonaka, K (2010) & $\frac{1}{10}$ & $0.11(0.02,0.29)$ & 2.20 \\
\hline Hirasawa, K (2010) & $\leftarrow$ & $0.02(0.00,0.10)$ & 6.08 \\
\hline Takahashi, H (2010) & $1 \rightarrow$ & $0.17(0.11,0.25)$ & 4.79 \\
\hline Repici, A (2010) & +2 & $0.05(0.00,0.25)$ & 2.46 \\
\hline Ishii, N (2010) & $1 \rightarrow$ & $0.24(0.12,0.41)$ & 1.98 \\
\hline Subtotal (I-squared $=68.4 \%, p=0.000)$ & 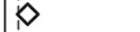 & $0.09(0.05,0.14)$ & 43.87 \\
\hline Overall $($ I-squared $=76.0 \%, p=0.000)$ & $\diamond$ & $0.05(0.03,0.08)$ & 100.00 \\
\hline \multicolumn{4}{|l|}{ NOTE: Weights are from random effects analysis } \\
\hline 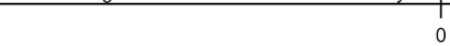 & $\begin{array}{l}1 \\
.5\end{array}$ & & \\
\hline
\end{tabular}

Figure 6 Forest plots of the proportion of patients developed mediastinal emphysema after ESD.

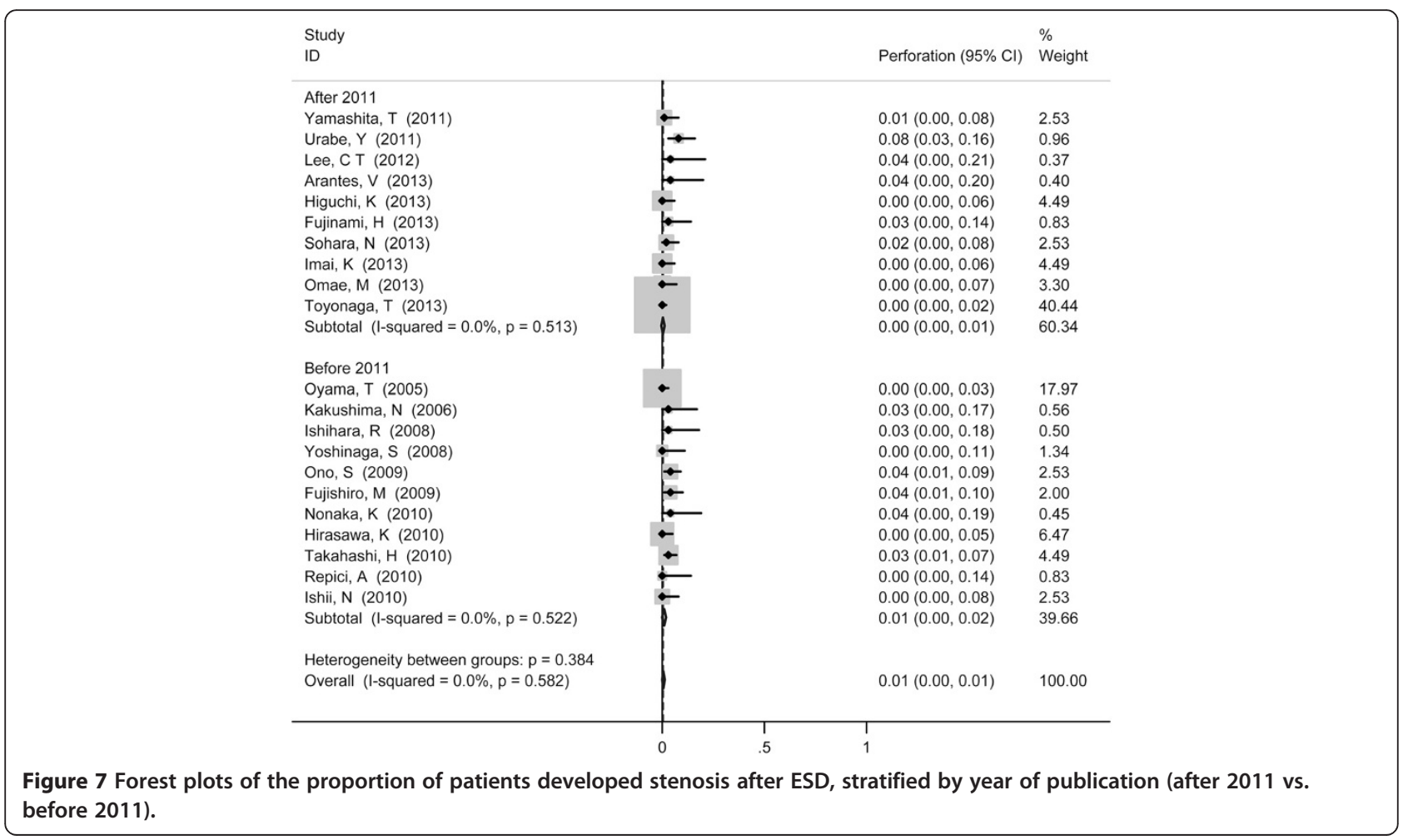




\begin{tabular}{|c|c|c|c|}
\hline Study & & mediastinal & \\
\hline ID & & emphysema $(95 \% \mathrm{Cl})$ & Weigh \\
\hline Oyama, T (2005) & $\rightarrow$ & $0.06(0.02,0.12)$ & 1.16 \\
\hline Kakushima, N (2006) & & $0.00(0.00,0.10)$ & 1.16 \\
\hline Ishihara, R (2008) & & $0.00(0.00,0.10)$ & 1.16 \\
\hline Yoshinaga, S (2008) & - & $0.00(0.00,0.11)$ & 0.96 \\
\hline Ono, S (2009) & - & $0.01(0.00,0.05)$ & 4.64 \\
\hline Fujishiro, M (2009) & - & $0.00(0.00,0.03)$ & 12.90 \\
\hline Nonaka, K (2010) & $\leftarrow$ & $0.00(0.00,0.11)$ & 0.96 \\
\hline Hirasawa, K (2010) & - & $0.00(0.00,0.05)$ & 4.64 \\
\hline Takahashi, H (2010) & - & $0.00(0.00,0.03)$ & 12.90 \\
\hline Repici, A (2010) & & $0.10(0.01,0.32)$ & 0.12 \\
\hline Ishii, N (2010) & $\frac{1}{-}$ & $0.00(0.00,0.08)$ & 1.81 \\
\hline Yamashita, T (2011) & $\leftarrow$ & $0.00(0.00,0.04)$ & 7.25 \\
\hline Urabe, Y (2011) & - & $0.00(0.00,0.04)$ & 7.25 \\
\hline Lee, CT (2012) & Fo. & $0.04(0.00,0.21)$ & 0.26 \\
\hline Arantes, V (2013) & - & $0.08(0.01,0.26)$ & 0.19 \\
\hline Higuchi, K (2013) & - & $0.00(0.00,0.06)$ & 3.22 \\
\hline Fujinami, H (2013) & & $0.21(0.10,0.37)$ & 0.16 \\
\hline Sohara, N (2013) & - & $0.00(0.00,0.05)$ & 4.64 \\
\hline Imai, K (2013) & $\div-$ & $0.00(0.00,0.06)$ & 3.22 \\
\hline Omae, M (2013) & $\div$ & $0.00(0.00,0.07)$ & 2.37 \\
\hline Toyonaga, T (2013) & - & $0.00(0.00,0.02)$ & 29.02 \\
\hline Overall (I-squared $=0.0 \%, p=0.541$ ) & & $0.00(0.00,0.01)$ & 100.00 \\
\hline
\end{tabular}

Figure 8 Forest plots of perforation rate during ESD, stratified by year of publication (after 2011 vs. before 2011).

occurrence. For example, in some centers, lesions that occupied $>3 / 4$ esophageal circumference may not suitable for ESD during recent years. Nevertheless, improvements of surgical techniques and devices during last few years should not be ignored. It is demonstrated in Table 1 that the insulation-tipped knife was more widely used in combination of devices after 2011. Before that, hook knife and flex knife were the mainstay devices used in each center. Fujinami et al. reported that the use of the stag beetle (SB) knife for esophageal ESD reduced the risk of complications [16]. Moreover, efficient intervention decreased the incidence and severity of stenosis after endoscopic resection involving more than $75 \%$ circumference when preventative dilatation was carried out [31]. Among these interventions, the scheduled endoscopic balloon dilatation (EBD) after ESD and local injection of steroids were the most applied methods. EBD has been a choice in the setting of benign esophageal strictures [35-37]. Local steroid injection into corrosive or anastomotic strictures could achieve remission of dysphagia, with $26.5 \%$ to $56 \%$ less incidence compared to control groups without intralesional steroid injection [38-40].

It is considered that, compared with EMR, ESD showed a better en bloc and R0 resection rate for the treatment of superficial esophageal tumors, leading to a reduced local recurrence rate [31]. Our data of local recurrence showed a similar result that only 5 out of 1159 patients developed histopathologically identified local recurrence. This finding suggested that the possibility of local recurrence should not be overlooked even after R0 resection. Thus, we suggest patients should be maintained in a scheduled surveillance program.

Although stratification by tumor size showed higher R0 resection rate for small tumor $(\mathrm{D}<25 \mathrm{~mm})$, heterogeneity was not fully explained. Also, heterogeneity of incidence of stenosis was significant across included studies. It was not surprising owing to the difference in patient samples, settings and protocols, instruments and provider factors. As for stenosis, different center may use different modalities to prevent the occurrence of stenosis, which may explain the significant heterogeneity.

There were also several limitations in this study. First, since most of the included studies were conducted in Japan, it can hardly represent the basic characteristics of patients worldwide. Further efforts should be focused on conducting clinical trials in western centers for further research. Second, heterogeneity was not fully explained. Heterogeneity of R0 resection rate for small tumor and incidence of stenosis were significant. Third, follow-up duration was not long enough which may lead to the underestimation of recurrence rate.

\section{Conclusions}

In summary, this systematic review and meta-analysis showed that (1) ESD was an efficient modality for treating SEC, with perfect en bloc and R0 resection rate and 
low complication rate; (2) Compared with large tumor (D $\geq 25 \mathrm{~mm})$, ESD for small tumor $(\mathrm{D}<25 \mathrm{~mm})$ had a higher R0 resection rate; (3) The incidence of stenosis dropped recently compared with several years ago.

\section{Abbreviations}

ESD: Endoscopic submucosal dissection; EMR: Endoscopic mucosal resection; SEC: Superficial esophageal carcinoma; RFA: Radiofrequency ablation; EBD: Endoscopic balloon dilatation; Cl: Confidential interval.

\section{Competing interests}

The authors declare that they have no competing interest.

\section{Authors' contributions}

$\mathrm{JH}$ conceived and designed the study. FS analyzed data and wrote the manuscript. PY helped with analysis and data collection. TC helped in data interpretation and date collection. All authors read and approved the final manuscript.

\section{Acknowledgements}

The authors would like to thank all participants and research staff.

\section{Funding}

This article was supported by National Natural Science Foundation of China (31170720, 81301996), The Ph.D. Programs Foundation of Ministry of Education of China (20130101120017), Zhejiang Provincial Natural Science Foundation of China (LQ13H160012), Medical Science and Technology Project of Department of Health of Zhejiang Provincial Government (2013KYA070).

Received: 14 January 2014 Accepted: 24 April 2014

Published: 7 May 2014

\section{References}

1. Parkin DM, Bray Fl, Devesa SS: Cancer burden in the year 2000. The global picture. Eur J Cancer 2001, 37:4-66

2. Ishihara R, lishi H, Uedo N, Takeuchi Y, Yamamoto S, Yamada T, Masuda E, Higashino K, Kato M, Narahara H, Tatsuta M: Comparison of EMR and endoscopic submucosal dissection for en bloc resection of early esophageal cancers in Japan. Gastrointest Endosc 2008, 68:1066-1072.

3. Ono H, Kondo H, Gotoda T, Shirao K, Yamaguchi H, Saito D, Hosokawa K, Shimoda T, Yoshida S: Endoscopic mucosal resection for treatment of early gastric cancer. Gut 2001, 48:225-229.

4. Oyama T, Tomori A, Hotta K, Morita S, Kominato K, Tanaka M, Miyata Y: Endoscopic submucosal dissection of early esophageal cancer. Clin Gastroenterol Hepatol 2005, 3:S67-S70.

5. Fujishiro M, Yahagi N, Kakushima N, Kodashima S, Muraki Y, Ono S, Yamamichi N, Tateishi A, Shimizu Y, Oka M, Ogura K, Kawabe T, Ichinose M, Omata M: Endoscopic submucosal dissection of esophageal squamous cell neoplasms. Clin Gastroenterol Hepatol 2006, 4:688-694.

6. Yamashita T, Zeniya A, Ishii H, Tsuji T, Tsuda S, Nakane K, Komatsu M: Endoscopic mucosal resection using a cap-fitted panendoscope and endoscopic submucosal dissection as optimal endoscopic procedures for superficial esophageal carcinoma. Surg Endosc 2011, 25:2541-2546.

7. Yoshinaga S, Gotoda T, Kusano C, Oda I, Nakamura K, Takayanagi R: Clinical impact of endoscopic submucosal dissection for superficial adenocarcinoma located at the esophagogastric junction. Gastrointest Endosc 2008, 67:202-209.

8. Fujishiro M, Kodashima S, Goto O, Ono S, Niimi K, Yamamichi N, Oka M, Ichinose M, Omata M: Endoscopic submucosal dissection for esophageal squamous cell neoplasms. Dig Endosc 2009, 21:109-115.

9. Repici A, Hassan C, Carlino A, Pagano N, Zullo A, Rando G, Strangio G, Romeo F, Nicita R, Rosati R, Malesci A: Endoscopic submucosal dissection in patients with early esophageal squamous cell carcinoma: results from a prospective Western series. Gastrointest Endosc 2010, 71:715-721.

10. Ono S, Fujishiro M, Niimi K, Goto O, Kodashima S, Yamamichi N, Omata M: Long-term outcomes of endoscopic submucosal dissection for superficial esophageal squamous cell neoplasms. Gastrointest Endosc 2009, 70:860-866
11. Stroup DF, Berlin JA, Morton SC, Olkin I, Williamson GD, Rennie D, Moher D, Becker BJ, Sipe TA, Thacker SB: Meta-analysis of observational studies in epidemiology. J Amer Med Assoc 2000, 283:2008-2012.

12. Downs $\mathrm{SH}$, Black N: The feasibility of creating a checklist for the assessment of the methodological quality both of randomised and non-randomised studies of health care interventions. J Epidemiol Community Health 1998, 52:377-384.

13. Higgins J, Thompson SG: Quantifying heterogeneity in a meta-analysis. Stat Med 2002, 21:1539-1558.

14. Arantes V, Albuquerque W, Freitas Dias CA, Demas Alvares Cabral MM Yamamoto H: Standardized endoscopic submucosal tunnel dissection for management of early esophageal tumors (with video). Gastrointest Endosc 2013, 78:946-952

15. Higuchi K, Tanabe S, Azuma M, Katada C, Sasaki T, Ishido K, Naruke A, Katada N, Koizumi W: A phase II study of endoscopic submucosal dissection for superficial esophageal neoplasms (KDOG 0901). Gastrointest Endosc 2013, 78:704-710.

16. Fujinami H, Hosokawa A, Ogawa K, Nishikawa J, Kajiura S, Ando T, Ueda A, Yoshita $\mathrm{H}$, Sugiyama T: Endoscopic submucosal dissection for superficial esophageal neoplasms using the stag beetle knife. Dis Esophagus 2014, 27(1):50-54.

17. Sohara N, Hagiwara S, Arai R, lizuka H, Onozato Y, Kakizaki S: Can endoscopic submucosal dissection be safely performed in a smaller specialized clinic? World J Gastroenterol 2013, 19:528-535.

18. Imai K, Kakushima N, Tanaka M, Takizawa K, Matsubayashi H, Hotta K, Yamaguchi Y, Ono H: Validation of the application of the Japanese curative criteria for superficial adenocarcinoma at the esophagogastric junction treated by endoscopic submucosal dissection: a long-term analysis. Surg Endosc 2013, 27:2436-2445.

19. Omae M, Fujisaki J, Horiuchi Y, Yoshizawa N, Matsuo Y, Kubota M, Suganuma T, Okada K, Ishiyama A, Hirasawa T, Yamamoto Y, Tsuchida T, Hoshino E, Igarashi M: Safety, efficacy, and long-term outcomes for endoscopic submucosal dissection of early esophagogastric junction cancer. Gastric Cancer 2013, 16:147-154.

20. Toyonaga T, Man-i M, East JE, Nishino E, Ono W, Hirooka T, Ueda C, Iwata Y, Sugiyama T, Dozaiku T, Hirooka T, Fujita T, Inokuchi H, Azuma T: 1,635 Endoscopic submucosal dissection cases in the esophagus, stomach, and colorectum: complication rates and long-term outcomes. Surg Endosc 2013, 27:1000-1008

21. Lee $C T$, Chang $C Y$, Tai CM, Wang WL, Tseng CH, Hwang JC, Lin JT: Endoscopic submucosal dissection for early esophageal neoplasia: a single center experience in South Taiwan. J Formos Med Assoc 2012, 111:132-139.

22. Li QL, Zhou PH, Yao L, Xu MD, Zhang YQ, Zhong YS, Chen WF: Submucosal Tumors of the Esophagogastric Junction Originating From the Muscularis Propria Layer: A Large Study of Endoscopic Submucosal Dissection. Gastrointest Endosc 2012, 75S:157.

23. Shi Q, Zhong YS, Yao LQ, Zhou PH, Xu MD, Wang P: Endoscopic submucosal dissection for treatment of esophageal submucosal tumors originating from the muscularis propria layer. Gastrointest Endosc 2011, 74:1194-1200

24. Urabe Y, Hiyama T, Tanaka S, Yoshihara M, Arihiro K, Chayama K: Advantages of endoscopic submucosal dissection versus endoscopic oblique aspiration mucosectomy for superficial esophageal tumors. J Gastroenterol Hepatol 2011, 26:275-280.

25. Nonaka K, Arai S, Ishikawa K, Nakao M, Nakai Y, Togawa O, Nagata K, Shimizu M, Sasaki Y, Kita H: Short term results of endoscopic submucosal dissection in superficial esophageal squamous cell neoplasms. World J Gastrointest Endosc 2010, 2:69-74.

26. Hirasawa K, Kokawa A, Oka H, Yahara S, Sasaki T, Nozawa A, Tanaka K: Superficial adenocarcinoma of the esophagogastric junction: long-term results of endoscopic submucosal dissection. Gastrointest Endosc 2010, 72:960-966.

27. Takahashi H, Arimura Y, Masao H, Okahara S, Tanuma T, Kodaira J, Kagaya H, Shimizu Y, Hokari K, Tsukagoshi H, Shinomura Y, Fujita M: Endoscopic submucosal dissection is superior to conventional endoscopic resection as a curative treatment for early squamous cell carcinoma of the esophagus (with video). Gastrointest Endosc 2010, 72(255-264):261-264.

28. Ishii N, Horiki N, Itoh T, Uemura M, Maruyama M, Suzuki S, Uchida S, Izuka Y, Fukuda K, Fujita Y: Endoscopic submucosal dissection with a combination of small-caliber-tip transparent hood and flex knife is a safe and 
effective treatment for superficial esophageal neoplasias. Surg Endosc 2010, 24:335-342.

29. Kakushima N, Yahagi N, Fujishiro M, Kodashima S, Nakamura M, Omata M: Efficacy and safety of endoscopic submucosal dissection for tumors of the esophagogastric junction. Endoscopy 2006, 38:170-174.

30. Ohkuwa M, Hosokawa K, Boku N, Ohtu A, Tajiri H, Yoshida S: New endoscopic treatment for intramucosal gastric tumors using an insulated-tip diathermic knife. Endoscopy 2001, 33:221-226.

31. Koike T, Nakagawa K, lijima K, Shimosegawa T: Endoscopic resection (endoscopic submucosal dissection/endoscopic mucosal resection) for superficial Barrett's esophageal cancer. Dig Endosc 2013, 25(Suppl 1):20-28.

32. Sgourakis G, Gockel I, Lang H: Endoscopic and surgical resection of T1a/ T1b esophageal neoplasms: a systematic review. World I Gastroenterol 2013, 19:1424-1437.

33. Katada C, Muto M, Manabe T, Boku N, Ohtsu A, Yoshida S: Esophageal stenosis after endoscopic mucosal resection of superficial esophageal lesions. Gastrointest Endosc 2003, 57:165-169.

34. Ono S, Fujishiro M, Niimi K, Goto O, Kodashima S, Yamamichi N, Omata M: Predictors of postoperative stricture after esophageal endoscopic submucosal dissection for superficial squamous cell neoplasms. Endoscopy 2009, 41:661-665.

35. Isomoto H, Yamaguchi N, Nakayama T, Hayashi T, Nishiyama H, Ohnita K, Takeshima F, Shikuwa S, Kohno S, Nakao K: Management of esophageal stricture after complete circular endoscopic submucosal dissection for superficial esophageal squamous cell carcinoma. BMC Gastroenterol 2011 , 11:46.

36. Isomoto $\mathrm{H}$, Yamaguchi $\mathrm{N}$ : Endoscopic submucosal dissection in the era of proton pump inhibitors. J Clin Biochem Nutr 2009, 44:205.

37. Ezoe Y, Muto M, Horimatsu T, Morita S, Miyamoto S, Mochizuki S, Minashi K, Yano T, Ohtsu A, Chiba T: Efficacy of preventive endoscopic balloon dilation for esophageal stricture after endoscopic resection. J Clin Gastroenterol 2011, 45:222-227.

38. Yamaguchi N, Isomoto H, Nakayama T, Hayashi T, Nishiyama H, Ohnita K, Takeshima F, Shikuwa S, Kohno S, Nakao K: Usefulness of oral prednisolone in the treatment of esophageal stricture after endoscopic submucosal dissection for superficial esophageal squamous cell carcinoma. Gastrointest Endosc 2011, 73:1115-1121.

39. Hashimoto S, Kobayashi M, Takeuchi M, Sato Y, Narisawa R, Aoyagi Y: The efficacy of endoscopic triamcinolone injection for the prevention of esophageal stricture after endoscopic submucosal dissection. Gastrointest Endosc 2011, 74:1389-1393.

40. Hanaoka N, Ishihara R, Takeuchi Y, Uedo N, Higashino K, Ohta T, Kanzaki H, Hanafusa M, Nagai K, Matsui F: Intralesional steroid injection to prevent stricture after endoscopic submucosal dissection for esophageal cancer: a controlled prospective study. Endoscopy 2012, 44:1007-1011.

doi:10.1186/1749-8090-9-78

Cite this article as: Sun et al:: Efficacy and complication of endoscopic submucosal dissection for superficial esophageal carcinoma: a systematic review and meta-analysis. Journal of Cardiothoracic Surgery 2014 9:78.

\section{Submit your next manuscript to BioMed Central and take full advantage of:}

- Convenient online submission

- Thorough peer review

- No space constraints or color figure charges

- Immediate publication on acceptance

- Inclusion in PubMed, CAS, Scopus and Google Scholar

- Research which is freely available for redistribution 